\title{
Long-term results of radiotherapy combined with nedaplatin and 5 -fluorouracil for postoperative loco-regional recurrent esophageal cancer: update on a phase II study
}

Keiichi Jingu ${ }^{1 *}$, Haruo Matsushita ${ }^{1}$, Ken Takeda', Rei Umezawa', Chiaki Takahashi', Toshiyuki Sugawara', Masaki Kubozono', Keiko Abe', Takaya Tanabe', Yuko Shirata', Takaya Yamamoto', Youjirou Ishikawa' and Kenji Nemoto ${ }^{2}$

\begin{abstract}
Background: In 2006, we reported the effectiveness of chemoradiotherapy for postoperative recurrent esophageal cancer with a median observation period of 18 months. The purpose of the present study was to update the results of radiotherapy combined with nedaplatin and 5-fluorouracil (5-FU) for postoperative loco-regional recurrent esophageal cancer.

Methods: Between 2000 and 2004, we performed a phase II study on treatment of postoperative loco-regional recurrent esophageal cancer with radiotherapy ( $60 \mathrm{~Gy} / 30$ fractions/6 weeks) combined with chemotherapy consisting of two cycles of nedaplatin $\left(70 \mathrm{mg} / \mathrm{m}^{2} / 2 \mathrm{~h}\right)$ and $5-\mathrm{FU}\left(500 \mathrm{mg} / \mathrm{m}^{2} / 24 \mathrm{~h}\right.$ for 5 days).

The primary endpoint was overall survival rate, and the secondary endpoints were progression-free survival rate, irradiated-field control rate and chronic toxicity.

Results: A total of 30 patients were enrolled in this study. The regimen was completed in $76.7 \%$ of the patients. The median observation period for survivors was 72.0 months. The 5 -year overall survival rate was $27.0 \%$ with a median survival period of 21.0 months. The 5-year progression-free survival rate and irradiated-field control rate were $25.1 \%$ and $71.5 \%$, respectively. Grade 3 or higher late toxicity was observed in only one patient. Two long-term survivors had gastric tube cancer more than 5 years after chemoradiotherapy.

Pretreatment performance status, pattern of recurrence (worse for patients with anastomotic recurrence) and number of recurrent lesions (worse for patients with multiple recurrent lesions) were statistically significant prognostic factors for overall survival.

Conclusions: Radiotherapy combined with nedaplatin and 5-FU is a safe and effective salvage treatment for postoperative loco-regional recurrent esophageal cancer. However, the prognosis of patients with multiple regional recurrence or anastomotic recurrence is very poor.
\end{abstract}

Keywords: Postoperative recurrent esophageal cancer, Chemoradiotherapy, Long-term results, Phase II study

\footnotetext{
* Correspondence: kjingu-jr@rad.med.tohoku.ac.jp

'Department of Radiation Oncology, Tohoku University School of Medicine,

1-1 Seiryo-chou, Aoba-ku, Sendai 980-8574, Japan

Full list of author information is available at the end of the article
} 


\section{Background}

Extended radical esophagectomy with three-field (neck, mediastinum, and abdomen) lymph node dissection has been performed since the mid-1980's, and it seems to have improved survival of patients with esophageal cancer [1-3]. However, there is recurrence in $27-52 \%$ of operated patients and loco-regional recurrence in 41.5$55 \%$ of patients with postoperative recurrence [3-9]. In 2006, we reported the effectiveness of radiotherapy and concurrent chemotherapy for postoperative recurrent esophageal cancer with a median observation period of 18.0 months [10]. Although the results were better than those of other studies using radiotherapy with or without chemotherapy, the observation period was not sufficient. Furthermore, there have been no prospective studies with a long-term observation period for patients with postoperative loco-regional recurrent esophageal cancer.

The purpose of the present study was to update the results of the phase II study of definitive radiotherapy with nedaplatin (CDGP) and 5-fluorouracil (5-FU) for loco-regional recurrent esophageal cancer after curative resection.

\section{Methods}

The present study was performed between 2000 and 2004 in Tohoku University Hospital and two affiliated hospitals according to the following protocol.

All patients had histologically proven squamous cell carcinoma of the esophagus. Patient selection criteria included 1) 30 to 80 years of age, 2) Eastern Cooperative Oncology Group (ECOG) performance status of 0 to 3, 3) no other active cancer, 4) no serious cardiac, liver, or pulmonary disease, 5) creatinine clearance of more than $50 \mathrm{ml} / \mathrm{min}, 6$ ) adequate bone marrow function (leukocyte count of $4000 / \mu \mathrm{l}$, platelet count of $100,000 / \mu \mathrm{l}, 7)$ locoregional recurrence (including para-aortic lymph node metastasis) without distant metastasis after no residual tumor (R0) resection by extended radical esophagectomy with three-field (neck, mediastinum, and abdomen) lymph node dissection, and 8) no previous therapy other than $\mathrm{R} 0$ resection.

Recurrence was diagnosed comprehensively by upper gastrointestinal endoscopy, ultrasonography, computed tomography (CT), physical findings and/or cytology.

\section{Radiotherapy}

A linear accelerator (4 MV or $10 \mathrm{MV}$ ) was used as the $\mathrm{X}$-ray source. The target volume was localized for radiotherapy in all patients by CT planning. The daily fractional dose of radiotherapy was $2.0 \mathrm{~Gy}$, administered 5 days a week, and the total dose was 60.0 Gy. For 11 patients, a T-shaped field (including the bilateral supraclavicular, mediastinal and abdominal regions) was used. For the remaining 19 patients, extended local fields with a margin of 1 to $2 \mathrm{~cm}$ from the macroscopic tumor were used. After $40 \mathrm{~Gy}$, the field was changed in all patients to avoid the spinal cord, and only macroscopic lesions were irradiated with a margin of 1 to $1.5 \mathrm{~cm}$.

\section{Chemotherapy}

Each cycle of chemotherapy consisted of 120-minute infusion of CDGP at $70 \mathrm{mg} / \mathrm{m}^{2}$ and a 5 -day period of 5 -FU at $500 \mathrm{mg} / \mathrm{m}^{2} /$ day. This cycle of chemotherapy was repeated with an interval of 4 weeks, for a total radiotherapy dose of 60 Gy (Figure 1). When toxicity of grade 3 or higher was noted and prolonged, we suspended or discontinued chemotherapy or reduced the dose of CDGP alone or the dose of both CDGP and 5-FU by 25-30\% in the subsequent cycle.

Completion of the regimen in this study was defined as completion of two cycles of full-dose CDGP + 5-FU for a total radiotherapy dose of 60 Gy without suspension of treatment.

\section{Endpoint}

The primary endpoint of the present study was overall survival rate, and the secondary endpoints were progression-free survival rate, irradiated-field control rate and late toxicity.

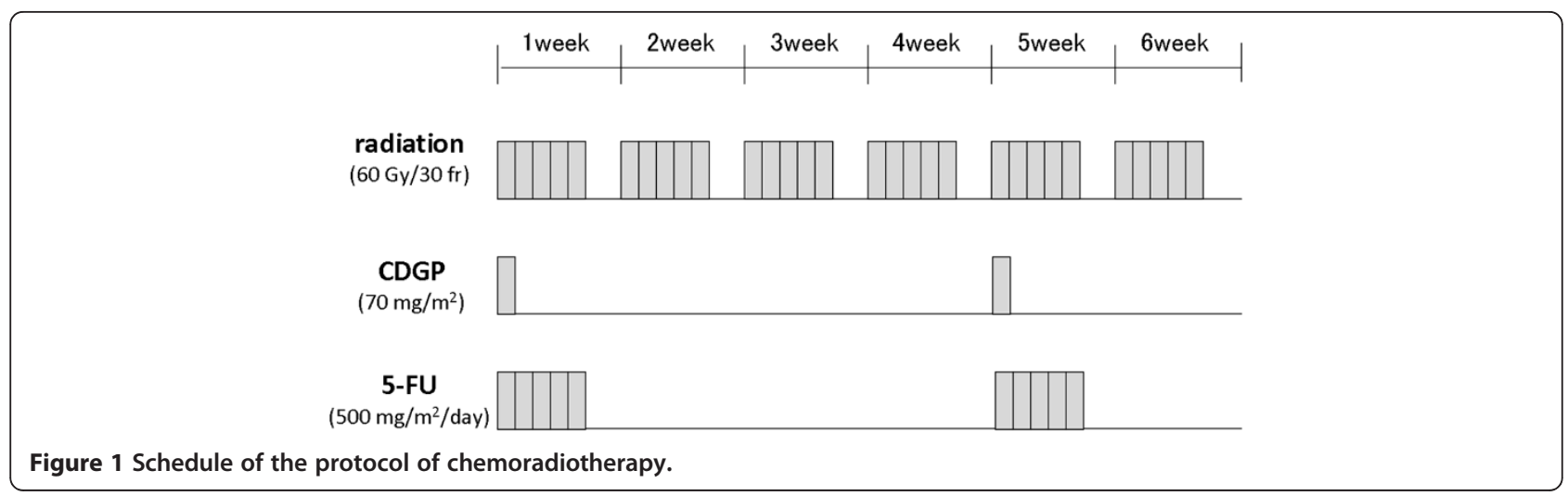


Table 1 Patients' characteristics

\begin{tabular}{|c|c|c|c|c|c|c|c|c|c|c|c|c|c|}
\hline $\begin{array}{l}\text { patient } \\
\text { number }\end{array}$ & age & gender & $\begin{array}{l}\text { preoperative } \\
\text { stage } \\
\text { (UICC*1997) }\end{array}$ & $\begin{array}{l}\text { time interval } \\
\text { between } \\
\text { surgery and } \\
\text { recurrence } \\
\text { (months) }\end{array}$ & $\begin{array}{l}\text { PS } \\
\text { (ECOG+) }\end{array}$ & $\begin{array}{l}\text { recurrent } \\
\text { regions }\end{array}$ & field & $\begin{array}{l}\text { number of } \\
\text { cycles of } \\
\text { chemo }\end{array}$ & $\begin{array}{l}\text { tumor } \\
\text { response } \\
\text { (RECIST*) }\end{array}$ & $\begin{array}{l}\text { irradiated } \\
\text { field } \\
\text { recurrence } \\
\text { (yes/no) }\end{array}$ & $\begin{array}{l}\text { recurrence } \\
\text { (yes/no) }\end{array}$ & $\begin{array}{l}\text { dead/ } \\
\text { alive }\end{array}$ & $\begin{array}{l}\text { survival } \\
\text { period } \\
\text { (months) }\end{array}$ \\
\hline 1 & 70 & male & $\| \mathrm{A}$ & 6 & 1 & $\begin{array}{l}\text { subclavicular/ } \\
\text { mediastinal }\end{array}$ & T-shaped & 2 & $P R$ & yes & yes & dead & 6.5 \\
\hline 2 & 64 & male & III & 6 & 1 & mediastinal & T-shaped & 2 & SD & yes & yes & dead & 14 \\
\hline 3 & 64 & male & $\| \mathrm{A}$ & 47 & 1 & $\begin{array}{l}\text { anastomosis/ } \\
\text { subclavicular/ } \\
\text { mediastinal }\end{array}$ & T-shaped & 2 & SD & no & yes & dead & 5 \\
\hline 4 & 50 & male & III & 12 & 1 & abdominal & local & 2 & PR & no & yes & dead & 8 \\
\hline 5 & 64 & male & III & 7 & 1 & $\begin{array}{l}\text { mediastinal/ } \\
\text { abdominal }\end{array}$ & local & 1 & SD & no & yes & dead & 5 \\
\hline 6 & 62 & male & III & 13 & 2 & anastomosis & T-shaped & 2 & $P R$ & no & yes & dead & 4 \\
\hline 7 & 55 & male & III & 5 & 3 & $\begin{array}{l}\text { anastomosis/ } \\
\text { subclavicular/ } \\
\text { abdominal }\end{array}$ & local & 2 & $P R$ & no & yes & dead & 5.5 \\
\hline 8 & 61 & female & $\| \mathrm{B}$ & 28 & 0 & mediastinal & T-shaped & 2 & $C R$ & no & no & alive & 54 \\
\hline 9 & 64 & male & III & 8 & 0 & $\begin{array}{l}\text { anastomosis/ } \\
\text { mediastinal }\end{array}$ & T-shaped & 2 & $C R$ & yes & yes & dead & 23.5 \\
\hline 10 & 62 & male & $\| \mathrm{B}$ & 22 & 1 & abdominal & local & 2 & PR & no & yes & dead & 10 \\
\hline 11 & 65 & male & I & 102 & 0 & mediastinal & T-shaped & 2 & $C R$ & no & no & alive & 90 \\
\hline 12 & 60 & male & IV B & 6 & 1 & subclavicular & local & 2 & PR & no & no & alive & 98 \\
\hline 13 & 72 & male & III & 7 & 0 & abdominal & local & 2 & PR & no & yes & dead & 39 \\
\hline 14 & 67 & male & III & 46 & 0 & subclavicular & T-shaped & 2 & $C R$ & no & no & alive & 49.5 \\
\hline 15 & 54 & male & n.a. & 4 & 0 & abdominal & local & 2 & SD & no & yes & dead & 12 \\
\hline 16 & 68 & male & III & 19 & 1 & $\begin{array}{l}\text { anastomosis/ } \\
\text { subclavicular }\end{array}$ & local & 2 & $P R$ & no & yes & dead & 33 \\
\hline 17 & 69 & male & III & 6 & 1 & $\begin{array}{l}\text { anastomosis/ } \\
\text { subclavicular }\end{array}$ & local & 2 & PR & no & yes & dead & 28.5 \\
\hline 18 & 68 & male & n.a. & 36 & 2 & mediastinal & local & 2 & PR & no & no & dead & 18.5 \\
\hline 19 & 62 & male & III & 10 & 1 & mediastinal & local & 2 & PR & no & no & alive & 16.5 \\
\hline 20 & 66 & male & IV B & 66 & 0 & subclavicular & local & 1 & PR & yes & yes & dead & 116 \\
\hline 21 & 57 & male & III & 11 & 3 & anastomosis & T-shaped & 2 & $\mathrm{PR}$ & no & no & dead & 8 \\
\hline 22 & 52 & male & III & 23 & 1 & mediastinal & T-shaped & 1 & PD & no & yes & dead & 6 \\
\hline 23 & 56 & male & 1 & 54 & 1 & anastomosis & local & 1 & PR & no & no & dead & 6 \\
\hline 24 & 62 & male & $\| \mathrm{B}$ & 23 & 0 & mediastinal & local & 2 & PR & no & no & alive & 125.5 \\
\hline 25 & 71 & male & I & 4 & 1 & subclavicular & local & 2 & SD & no & no & alive & 107 \\
\hline
\end{tabular}


Table 1 Patients' characteristics (Continued)

\begin{tabular}{|c|c|c|c|c|c|c|c|c|c|c|c|c|c|}
\hline 26 & 61 & male & I & 83 & 1 & abdominal & local & 2 & SD & yes & yes & dead & 42 \\
\hline 27 & 72 & male & III & 16 & 0 & mediastinal & local & 1 & SD & no & no & alive & 29 \\
\hline 28 & 71 & male & III & 6 & 2 & anastomosis & T-shaped & 2 & $C R$ & yes & yes & dead & 13.5 \\
\hline 29 & 63 & male & III & 39 & 0 & mediastinal & local & 2 & PR & no & yes & dead & 45 \\
\hline 30 & 72 & male & III & 4 & 1 & mediastinal & local & 2 & PR & no & yes & dead & 21 \\
\hline
\end{tabular}

* UICC: Union for International Cancer Control.

† ECOG: Eastern Cooperative Oncology Group.

\# RECIST: Response Evaluation Criteria in Solid Tumors. 


\section{Follow-up}

Follow-up evaluations were performed every 3-6 months for the first 2 years and every 12 months thereafter by endoscopy and CT.

Only progression disease (PD) according to Response Evaluation Criteria In Solid Tumors (RECIST) was defined as failure of the present regimen (relapse again).

\section{Toxicity}

Toxicity was graded according to the Common Terminology Criteria for Adverse Events (CTCAE v3.0). An adverse effect at more than 90 days after completion of chemoradiotherapy was defined as late toxicity.

\section{Statistics}

Survival estimates were calculated using the KaplanMeier method from the first date of radiotherapy, and differences were evaluated by the log-rank test. Age (65 years or less vs. more than 65 years), preoperative stage (I-II vs. III-IV: Union for International Cancer Control 1997 (UICC1997)), time interval between surgery and recurrence (12 months or less vs. more than 12 months), pre-radiotherapy performance status (0-1 vs. $2-3$ ), radiation field (local alone vs. T-shaped), acute tumor response according to RECIST (complete regression $(\mathrm{CR}) \sim$ partial regression $(\mathrm{PR})$ vs. stable disease (SD) PD), number of cycles of chemotherapy (one vs. two), pattern of recurrence (anastomotic vs. non-anastomotic) and number of recurrent regions (one region vs. multiple regions) were entered into the log-rank test. A $\mathrm{p}$ value of less than 0.05 was considered significant. All analyses were performed using SPSS 20.0.

The present study protocol was reviewed and approved by our institutional review board (No. 2012-1-129), and informed consent was obtained from each patient before conducting the treatment.

\section{Results}

From 2000 to 2004, a total of 30 patients (29 males, 1 female; median age, 64 years; age range, 50 to 72 years) were enrolled in this phase II study. Patient characteristics are shown in Table 1 . The rate of completion of this regimen without reduction of chemotherapy was $76.7 \%$. The median observation period was 72 months (range, 16.5 to 125.5 months) for patients who survived. At the last observation date, 18 of the 30 patients had relapse again. Twenty-two of the 30 patients died: deaths were due to progression disease in 19 patients, intercurrent diseases in 2 patients and an iatrogenic cause in one patient.

The 3-year and 5-year overall survival rates were $38.4 \%$ (95\% confidence interval $(\mathrm{CI})=20.8-56.5)$ and $27.0 \%$ (95\% CI $=10.3-43.7)$, respectively, with a median survival period of 21.0 months $(95 \% \mathrm{CI}=2.5-39.5)$. The 3-year and 5-year progression-free survival rates were 29.3\% (95\% CI $=12.8-45.9)$ and $25.1 \%$ (95\% CI $=9.1-$ 41.2), respectively, and both of the 3-year and 5-year irradiated-field control rates were $71.5 \%$ (95\% CI $=51.8$ 91.2) (Figure 2).

Acute toxicities have already been reported in our previous report [10]. As the major late toxicity, only one patient had grade 3 or higher toxicity. The patient died 6 months after completion of the protocol due to serious pericardial effusion. There was no other grade 3 or higher late toxicity, although grade 1 or 2 focal pulmonary fibrous change, pericardial effusion and/or pleural effusion were often observed. Although not toxicity, there were 2 patients who developed gastric tube cancer, which could be controlled with endoscopic submucosal dissection.

In log-rank test, the difference between overall survival rate in performance status $(\mathrm{p}=0.007)$, pattern of recurrence $(\mathrm{p}=0.014)$ and number of recurrent lesions $(\mathrm{p}=$ 0.003 ) were statistically significant (Table 2 ).

\section{Discussion}

There have been some studies on the effectiveness of radiotherapy with or without chemotherapy for treatment of postoperative recurrent esophageal cancer. In those studies, even the 2-year survival rates were only $15-31 \%$ with short-term observation (Table 3) [11-15]. We previously reported preliminary results of the present study, which were excellent. Here, updated results with long-term observation are reported. Although the results are worse than those in the past preliminary report [10], the results of the current regimen remain one of the best achievements for patients with postoperative loco-regional recurrent esophageal cancer.

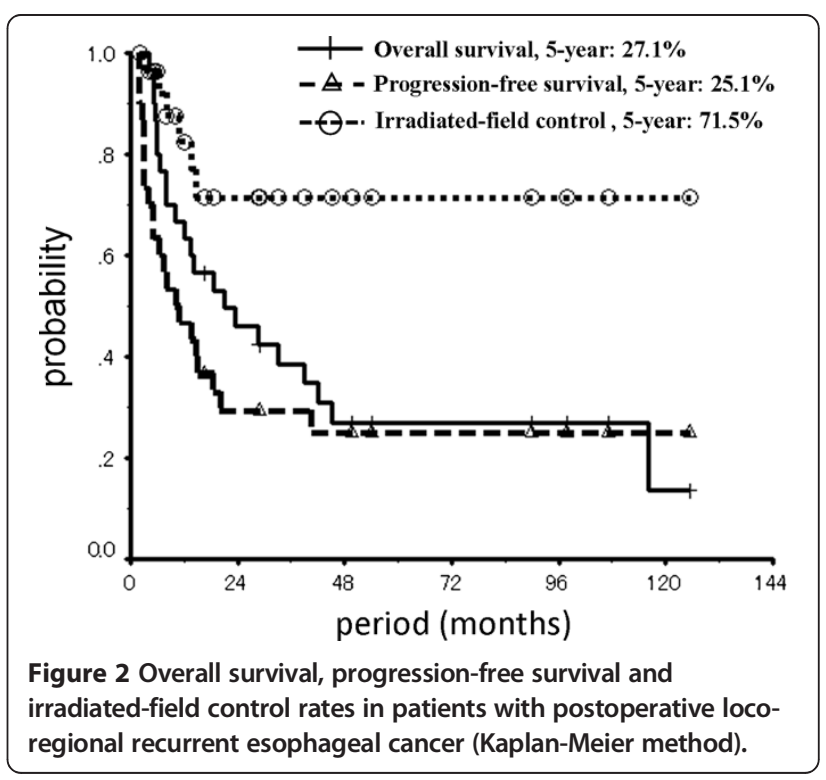


Table 2 Prognostic factors for overall survival

\begin{tabular}{|c|c|c|c|c|}
\hline factor & group & No. & $\begin{array}{l}\text { median survival } \\
\text { period (month) }\end{array}$ & $\begin{array}{c}\text { log-rank } \\
\text { p value }\end{array}$ \\
\hline \multirow[t]{2}{*}{ performance status } & $0-1$ & 25 & 33.0 & 0.007 \\
\hline & $2-3$ & 5 & 8.0 & \\
\hline \multirow[t]{2}{*}{ age } & $\geq 65$ & 12 & 33.0 & 0.172 \\
\hline & $<65$ & 18 & 10.0 & \\
\hline \multirow[t]{2}{*}{ preoperative stage (UICC§ 1997) } & $|-| \mid$ & 9 & 42.0 & 0.229 \\
\hline & III- IV & 21 & 21.0 & \\
\hline \multirow[t]{2}{*}{ number of cycles of chemotherapy } & 1 & 5 & 6.0 & 0.577 \\
\hline & 2 & 25 & 23.5 & \\
\hline \multirow[t]{2}{*}{ time interval between surgery and recurrence } & $\leq 12$ & 15 & 14.0 & 0.176 \\
\hline & $>12$ & 15 & 42.0 & \\
\hline \multirow[t]{2}{*}{ tumor response (RECIST*) } & CR-PR & 22 & 23.5 & 0.466 \\
\hline & SD-PD & 8 & 12.0 & \\
\hline \multirow[t]{2}{*}{ field } & local & 19 & 33.0 & 0.480 \\
\hline & T-shaped & 11 & 13.5 & \\
\hline \multirow[t]{2}{*}{ number of recurrent regions } & one & 23 & 39.0 & 0.014 \\
\hline & multiple & 7 & 6.5 & \\
\hline \multirow[t]{2}{*}{ pattern of recurrence } & anastomotic & 9 & 8.0 & 0.003 \\
\hline & non-anastomotic & 21 & 42.0 & \\
\hline
\end{tabular}

§UICC: Union for International Cancer Control, *RECIST: Response Evaluation Criteria in Solid Tumors.

Recurrence after surgery can now be detected earlier due to improvements in the resolution of CT. It might improve recently the treatment results for postoperative loco-regional recurrent esophageal cancer. FDG-PET/ $\mathrm{CT}$, which enables detection of recurrence at an earlier stage than that by only CT, has been used frequently since the mid-2000's for esophageal cancer, and the prognosis of loco-regional recurrent esophageal cancer may therefore be further improved.

We previously reported excellent results of chemoradiotherapy for solitary lymph node metastasis after curative surgery for esophageal cancer [16], and the results for patients with recurrence in one region were also significantly better than those for patients with recurrence in more than one region in the present study. This supports our hypothesis that the concept of oligo- recurrence [17] might also be applicable to postoperative esophageal cancer, especially in cases without anastomotic recurrence.

The appropriate irradiation field for postoperative loco-regional recurrent esophageal cancer has not been clarified. In the present study, there were some patients in whom recurrent lesions could not be controlled, but there were no patients who had regional lymph node recurrence after chemoradiotherapy. In our previous study on solitary lymph node metastasis [16], there were 2 patients who showed other lymph node metastases after chemoradiotherapy, but both of those patients had undergone irradiation with a T-shaped field. Furthermore, patients who were treated with a T-shaped field had a significantly higher rate of adverse events than did patients who were treated with a local field [10]. In the

Table 3 Contents and results of radiotherapy (with or without chemotherapy) for postoperative recurrent esophageal cancer in past studies

\begin{tabular}{|c|c|c|c|c|c|c|}
\hline author & year & No. & regimen & $\begin{array}{c}\text { median } \\
\text { observation period }\end{array}$ & $\begin{array}{c}\text { 2-year } \\
\text { survival rate }\end{array}$ & $\begin{array}{c}\text { 5-year } \\
\text { survival rate }\end{array}$ \\
\hline J Raoul ${ }^{12)}$ & 1995 & 24 & $\mathrm{RT}++\mathrm{CDDP}^{*}+5-\mathrm{FU}$ & 14 months & $17.1 \%$ & n.a. $\neq$ \\
\hline $\mathrm{K} \mathrm{Nemoto}^{13)}$ & 2001 & 33 & $\begin{array}{l}\text { RT alone (21) or RT + } \\
\text { CDDP+ 5-FU (12) }\end{array}$ & n.a. & $15 \%$ & n.a. \\
\hline Y Nishimura ${ }^{11)}$ & 2003 & 13 & $\mathrm{RT}+\mathrm{CDDP}+5-\mathrm{FU}$ & 9.5 months & $19 \%$ & n.a. \\
\hline Y Shioyama $^{14)}$ & 2007 & 82 & RT \pm chemotherapy & n.a. & $22 \%$ & $11 \%$ \\
\hline K Maruyama $^{15)}$ & 2011 & 23 & $\mathrm{RT} \pm$ chemotherapy & n.a. & $31 \%$ & $24 \%$ \\
\hline Current study & 2012 & 30 & $\mathrm{RT}+\mathrm{CDGP} \S+5-\mathrm{FU}$ & 72 months & $46.0 \%$ & $27.0 \%$ \\
\hline
\end{tabular}

†RT: radiotherapy, ${ }^{*}$ CDDP: cisplatin, § CDGP: nedaplatin, \# 5-FU: 5-fluorouracil, „n.a.: not available. 
present study, there was no late toxicity in the gastric tube even with $60 \mathrm{~Gy}$; however, there have been some reports of problems in the gastric tube caused by obstruction of blood flow $[18,19]$, which can be induced by radiation. Therefore, we do not recommend irradiation with a prophylactic field such as a T-shaped field for postoperative loco-regional recurrent esophageal cancer. Furthermore, Zhang et al. reported that results for patients treated with 60 Gy or more were significantly better than results for patients treated with less than $60 \mathrm{~Gy}$ in patients with postoperative loco-regional recurrent esophageal cancer [20], and we reported in 2001 that one of our patients died of necrosis of the gastric tube 6 months after the end of 66 Gy radiotherapy [13]. According to those reports and the present results, the appropriate radiation dose for loco-regional recurrent esophageal cancer might be $60 \mathrm{~Gy}$.

In the present study, 2 of the 5 patients who survived for more than 5 years after chemoradiotherapy had gastric tube cancer, which fortunately could be completely resected by endoscopic submucosal resection (ESD). In the past, when esophageal cancer patients seldom survived for a long time, the occurrence of gastric tube cancer was considered to be infrequent [21]. Recent improvements in the survival of patients after esophagectomy, however, have led to increasing occurrence of gastric tube cancer $[22,23]$. Bamba et al. reported that the 10-year cumulative incidence of gastric tube cancer after esophagectomy was $8.6 \%$ [24], and they described the possible cause of the high incidence of gastric cancer after esophagectomy. Asian people have a high rate of Helicobacter pylori infection and therefore have a high risk of gastric cancer [25]. Upper gastrointestinal endoscopy once or twice per year is recommended for follow-up after treatment for postoperative locoregional recurrent esophageal cancer. Gastric tube cancer is one of the major complicating diseases in patients who survive for a long time after treatment of esophageal cancer.

\section{Conclusions}

The present protocol of radiotherapy combined with CDGP and 5-FU is a safe and effective salvage treatment for postoperative loco-regional recurrent esophageal cancer. However, the prognosis of patients with multiple regional recurrence or anastomotic recurrence is very poor.

\section{Competing interests}

The authors declare that they have no competing interests.

\section{Author's contributions}

$\mathrm{KJ}$ drafted the manuscript and performed statistical analysis. KN participated in the study design and coordination. HM, CT, KT, TS, RU, MK, KA, TT, TY, YS and $Y$ performed the chemoradiotherapy and the follow-up. All of the authors have read and approved the final manuscript.

\section{Author details}

'Department of Radiation Oncology, Tohoku University School of Medicine, 1-1 Seiryo-chou, Aoba-ku, Sendai 980-8574, Japan. ${ }^{2}$ Department of Radiation Oncology, Yamagata University School of Medicine, Yamagata, Japan.

Received: 8 August 2012 Accepted: 20 November 2012 Published: 22 November 2012

\section{References}

1. Akiyama $H$, Tsurumaru M, Udagawa H, Kajiyama Y: Radical lymph node dissection for cancer of the thoracic esophagus. Ann Surg 1994, 220:364-373.

2. Fujita H, Kakegawa T, Yamana H, Shima I, Toh Y, Tomita Y, Fujii T, Yamasaki K, Higaki K, Noake T, Ishibashi N, Mizutani K: Mortality and morbidity rates, postoperative course, quality of life, and prognosis after extended radical lymphadenectomy for esophageal cancer. Ann Surg 1995, 222:654-662.

3. Nakagawa S, Kanda T, Kosugi S, Ohashi M, Suzuki T, Hatakeyama K: Recurrence pattern of squamous cell carcinoma of the thoracic esophagus after extended radical esophagectomy with three-field lymphadenectomy. J Am Coll Surg 2004, 198:205-211.

4. Law SY, Fok M, Wong J: Pattern of recurrence after oesophageal resection for cancer: clinical implications. Br J Surg 1996, 83:107-111.

5. Bhansali MS, Fujjta H, Kakegawa T, Yamana H, Ono T, Hikita S, Toh Y, Fujii T, Tou U, Shirouzu K: Pattern of recurrence after extended radical esophagectomy with three-field lymph node dissection for squamous cell carcinoma in the thoracic esophagus. World J Surg 1997, 21:275-281.

6. Kato H, Miyazaki T, Nakajima M, Sohda M, Fukai Y, Masuda N, Fukuchi M, Manda R, Tsukada K, Kuwano H: Prediction of hematogenous recurrence in patients with esophageal carcinoma. Jpn J Thorac Cardiovasc Surg 2003, 51:599-608.

7. Hulscher JB, van Sandick JW, Tijssen JG, Obertop H, van Lanschot JJ: The recurrence pattern of esophageal carcinoma after transhiatal resection. J Am Coll Surg 2000, 191:143-148.

8. Kyriazanos ID, Tachibana M, Shibakita M, Yoshimaru H, Kinugasa S, Dhar DK, Nakamoto T, Fujii T, Nagasue N: Pattern of recurrence after extended esophagectomy for squamous cell carcinoma of the esophagus. Hepatogastroenterology 2003, 50:115-120.

9. Fahn $\mathrm{HJ}$, Wang LS, Huang BS, Huang MH, Chien KY: Tumor recurrence in long-term survivors after treatment of carcinoma of the esophagus. Ann Thorac Surg 1994, 57:677-681.

10. Jingu K, Nemoto K, Matsushita H, Takahashi C, Ogawa Y, Sugawara T, Nakata E, Takai Y, Yamada S: Results of radiation therapy combined with nedaplatin (cis-diammine-glycoplatinum) and 5-fluorouracil for postoperative locoregional recurrent esophageal cancer. BMC Cancer. 2006, 6:50.

11. Nishimura Y, Koike R, Nakamatsu K, Kanamori S, Suzuki M, Shigeoka H, Shiozaki H: Concurrent chemoradiotherapy with protracted infusion of 5-FU and Cisplatin for postoperative recurrent or residual esophageal cancer. Jpn J Clin Oncol 2003, 33:341-345.

12. Raoul JL, Le Prise E, Meunier B, Julienne V, Etienne PL, Gosselin M, Launois $B$ : Combined radiochemotherapy for postoperative recurrence of oesophageal cancer. Gut 1995, 37:174-176.

13. Nemoto K, Ariga H, Kakuto Y, Matsushita H, Takeda K, Takahashi C, Takai Y, Yamada S, Hosoi Y: Radiation therapy for loco-regionally recurrent esophageal cancer after surgery. Radiother Oncol 2001, 61:165-168.

14. Shioyama Y, Nakamura K, Ohga S, Nomoto S, Sasaki T, Yamaguchi T, Toba T, Yoshitake T, Terashima H, Honda H: Radiation therapy for recurrent esophageal cancer after surgery: clinical results and prognostic factors. Jpn J Clin Oncol 2007, 37:918-923.

15. Maruyama K, Motoyama S, Anbai A, Usami S, Sato Y, Shibuya K, Yoshino K, Nakatsu T, Minamiya Y, Ogawa Jl: Therapeutic strategy for the treatment of postoperative recurrence of esophageal squamous cell carcinoma: clinical efficacy of radiotherapy. Dis Esophagus 2011, 24:166-171.

16. Jingu K, Ariga H, Nemoto K, Narazaki K, Umezawa R, Takeda K, Koto M, Sugawara T, Kubozono M, Miyata G, Onodera K, Yamada S: Long-term results of radiochemotherapy for solitary lymph node metastasis after curative resection of esophageal cancer. Int J Radiat Oncol Biol Phys 2012, 83:172-177

17. Niibe $Y$, Hayakawa $K$ : Oligometastases and oligo-recurrence: the new era of cancer therapy. Jpn $J$ Clin Oncol 2010, 40:107-111. 
18. Iwata N, Kuniyasu K, Hirai T, Yamashita Y, Yoshimoto A, Kuwahara M, Toge T: Pathological study on the mucosal damage of gastric replacement of the esophagus after the postoperative radiation. J Jpn Surg AssoC 1997, 58:2784-2790. in Japanese with English abstract.

19. Lin $F C$, Russell $H$, Ferguson MK: Strangulation of the reconstructive gastric tube by the azygos arch. Ann Thorac Surg 2006, 82:8-10

20. Zhang J, Peng F, Li N, Liu Y, Xu Y, Zhou L, Wang J, Zhu J, Huang M, Gong Y: Salvage concurrent radio-chemotherapy for postoperative local recurrence of squamous-cell esophageal cancer. Radiat Oncol 2012, 7(1):93.

21. Earlam R, Cunha-Melo JR: Oesophageal squamous cell carcinoma: i a critical review of surgery. Br J Surg 1980, 67:381-390.

22. Sugiura T, Kato H, Tachimori Y, Igaki H, Yamaguchi H, Nakanishi Y: Second primary carcinoma in the gastric tube constructed as an esophageal substitute after esophagectomy. J Am Coll Surg 2002, 194:578-583.

23. Kise Y, Kijima H, Shimada H, Tanaka H, Kenmochi T, Chino O, Tajima T, Makuuchi H: Gastric tube cancer after esophagectomy for esophageal squamous cell cancer and its relevance to Helicobacter pylori. Hepatogastroenterology 2003, 50:408-411.

24. Bamba T, Kosugi S, Takeuchi M, Kobayashi M, Kanda T, Matsuki A, Hatakeyama K: Surveillance and treatment for second primary cancer in the gastric tube after radical esophagectomy. Surg Endosc 2010, 24:1310-1317.

25. Uemura N, Okamoto S, Yamamoto S, Matsumura N, Yamaguchi S, Yamakido M, Taniyama K, Sasaki N, Schlemper RJ: Helicobacter pylori infection and the development of gastric cancer. N Engl J Med 2001, 345:784-789.

doi:10.1186/1471-2407-12-542

Cite this article as: Jingu et al:: Long-term results of radiotherapy combined with nedaplatin and 5 -fluorouracil for postoperative loco-regional recurrent esophageal cancer: update on a phase II study. BMC Cancer 2012 12:542.

\section{Submit your next manuscript to BioMed Central and take full advantage of:}

- Convenient online submission

- Thorough peer review

- No space constraints or color figure charges

- Immediate publication on acceptance

- Inclusion in PubMed, CAS, Scopus and Google Scholar

- Research which is freely available for redistribution 